\title{
Las huellas de la enseñanza de la Historia del Arte en los institutos madrileños (1835-1936)
}

\author{
CARMEN RODRÍGUEZ GUERRERO'1 \\ T. BORJA BODELÓN RAMOS²
}
The traces Art History in secondary education schools (1835-1938)

\begin{abstract}
RESUMEN:
Este texto pretende ofrecer una relación de los materiales didácticos adquiridos, diseñados y conservados para la enseñanza de la asignatura de historia del arte en los dos institutos de mayor recorrido histórico, nos referimos al Instituto de San Isidro y al del Cardenal Cisneros de Madrid. El ajuar patrimonial, que se va a presentar ordenado cronológicamente, está compuesto por mapas, láminas murales, fotografías, placas de linterna, manuales y trabajos escolares con el objetivo de introducirnos en el contexto educativo $y$ justificar los modos de educar de los catedráticos de estas instituciones durante un siglo.
\end{abstract}

\section{PALABRAS CLAVE}

Instituto San Isidro, Instituto del Cardenal Cisneros, Madrid, educación secundaria. Historia del arte, materiales didácticos, placas de linterna.

\begin{abstract}
This text aims to provide a list of materials purchased, designed and maintained in the two institutes of higher historical value to the teaching of art history subject, we refer to the Institute of San Isidro and Cardinal Cisneros of Madrid.
\end{abstract}

The heritage, which will be presented in chronological order, consists of maps, wall charts, photographs, lantern slides, manuals and school works in order to introduce in the educational context and justify the ways of educating the professors of these institutions for a century.

\section{KEY WORDS}

Instituto San Isidro, Instituto del Cardenal Cisneros, Madrid, secondary education, History of art, learning materials, lantern slides.

\footnotetext{
${ }^{1}$ Carmen Rodríguez Guerrero, doctora en Historia de la Educación y profesora de educación secundaria en los IES San Isidro de Madrid y Cardenal Cisneros de Madrid

${ }^{2}$ Borja Bodelón Ramos Licenciado en Historia y doctorando en Historia del Arte (UNED). Es profesor de Historia del Arte en el IES Cardenal Cisneros
} 


\section{ACOTACIONES PRELIMINARES}

En el primer tercio del siglo XIX, Madrid es una ciudad en pleno proceso de metamorfosis, a la vez que se despoja de su camisa de villa se transforma en una metrópoli moderna. Madrid, corte y capital, sede del gobierno, centro de las comunicaciones y fortunas de todo el país, plataforma de todas las aspiraciones políticas, sociales y culturales, experimenta un gran crecimiento urbanístico y, acorde con los ensanches de la ciudad, surgen las necesidades de una formación específica para las clases medias: el bachillerato.

Nos vamos a centrar en las enseñanza secundaria, situada entre la primaria y la universidad, imprescindible para el acceso a cualquier puesto de relevancia, estudios que necesitan instituciones para diferenciar a la clase a la que van dirigidos, de ahí que, en 1845 , el ministro Pidal dicta un plan de estudios ${ }^{3}$ que va a crear un instituto de segunda enseñanza en cada provincia a excepción de Madrid, que debido al mayor número de habitantes que demandan educación, entiende que necesite dos, y por tanto, dos instituciones que ya existían -los Estudios Nacionales de San Isidro y el Instituto de Segunda Enseñanza de la Corte- se transforman en el Instituto de San Isidro y el del Noviciado, denominado del Cardenal Cisneros desde 1877.

\section{DOS HISTORIAS PARALELAS EN EL TIEMPO}

En la España contemporánea, la educación se estructura con carácter centralizado y jerarquizado de forma piramidal: desde 1845, los dos institutos de Madrid junto con los institutos de Guadalajara, Segovia, Toledo, Cuenca, Ciudad Real y Albacete forman parte del distrito universitario de Madrid y se adscriben a la Universidad Central.

La primera gran diferencia entre las dos instituciones educativas madrileñas la situamos en su propio origen. Por una parte, si nos referimos a los antecedentes del Instituto de San Isidro tenemos que recordar los Estudios de la Villa de Madrid, creados en 1346 y al colegio que la Compañía de Jesús va a fundar en 1560. En 1603, el Colegio de los jesuitas va a recibir la herencia de la emperatriz María de Austria para construir una iglesia y un nuevo edificio escolar, y, así, hasta 1767, se denomina Reales Estudios del Colegio Imperial de Madrid, con la finalidad principal de educar los nobles, futuros gobernantes del país y modelos de sus conciudadanos. Ahora bien, los jesuitas son expulsados del país tras los sucesos del motín de Esquilache (1766-1767). A partir de 1770, se denomina Reales Estudios de San Isidro y de nuevo va a ser gestionado por la Compañía de Jesús.

3 «Plan de estudios de 1845», en UTANDE IGUALADA, Miguel, Planes de Estudio de enseñanza Media (1787-1963), Madrid, Ministerio de. Educación Nacional, Dirección General de Enseñanzas Medias, 1964, pp.39-62. 
El siglo XIX fue realmente una vorágine de cambios en esta institución como lo fue la historia de nuestro país, recibiendo sucesivamente las siguientes denominaciones: Colegio Imperial y sus Reales Estudios (1816-1820), Universidad de Madrid (1821-1823), y nuevamente Colegio Imperial y sus Reales Estudios (18231836), periodo en el que vuelven los jesuitas para ser expulsados definitivamente y denominarse Estudios Nacionales de San Isidro y, a la vez, ceder algunos de sus espacios para sede de la Universidad Central ${ }^{4}$.

Por otra parte, en el siglo XVIII y primer tercio del siglo XIX la decadencia de la Universidad de Alcalá es manifiesta, los vaivenes de orden político hacen que se dude si hay que trasladarla a la capital. Pues, como ya hemos anticipado, en Madrid se decide el futuro del país pero no tiene universidad. Los estudios jurídicos y de cánones de la Universidad de Alcalá se trasladan a Madrid en 1836 y, un año después, los estudios de Filosofía. Esto motiva que la Dirección General de Estudios, institución del Antiguo Régimen, más tarde Consejo de Instrucción Publica solicite a la reina gobernadora organizar los estudios de filosofía en un instituto de segunda enseñanza de la Corte para los estudios menores y la facultad de Filosofía para los estudios superiores. De forma que el Instituto del Noviciado se considera heredero del humanismo del Cardenal Cisneros, su patrimonio guarda los vestigios de los antiguos colegios menores de San Idelfonso y de los Artistas ${ }^{5}$.

El Instituto del Cardenal Cisneros se crea sin edificio propio, comienza su recorrido en los locales del Seminario de Nobles que más tarde se traslada al convento de las Salesas Nuevas siempre acompañando a la Facultad de Filosofía y, finalmente, desde 1844 en el convento del noviciado de los jesuitas, donde comienza compartiendo siete aulas, dos laboratorios, un gabinete, el patio del rector y el sello "Ommia perfundat luce»-(el saber) todo lo inunda con su luz-con los estudios universitarios.

De esta forma, el traslado de la Universidad desde Alcalá a Madrid, bajo el nombre bien elocuente de Universidad Central y el plan de estudios de1845 van a tener un significado y unas repercusiones bien distintas en los dos institutos:

1. El Instituto de San Isidro ha de ceder parte de sus locales, para que se instalen aulas de las facultades de Farmacia, Medicina y la Escuela de Arquitectura, así como la Escuela de Diplomacia y la Escuela de Taquigrafía, mientras, el Instituto del Cardenal Cisneros hasta 1888 es un invitado de la Facultad de Filosofía.

2. La biblioteca del Instituto de San Isidro, con más de 80.000 volúmenes, se convierte en la biblioteca de la de la Universidad, mientras en el Instituto

\footnotetext{
${ }^{4}$ MARTIN VILLA, Rafael, «El Instituto de San Isidro» en Participación educativa $n^{\circ}$ 7, Revista Participación educativa, Consejo Escolar del Estado y Ministerio de Educación, Madrid 2007, pp. 60-65,

${ }^{5}$ FADÓN GUERRA, Isidro, «El Instituto del Cardenal Cisneros de Madrid» en Revista Participación educativa nำ 7 del Consejo Escolar del Estado, Madrid 2007, pp. 55-59.
} 
Cardenal Cisneros comienza a crearse una biblioteca escolar a partir de la promulgación de la ley Moyano (1858) para la que se cuenta con los ejemplares de la Universidad de Alcalá.

3. El Instituto de San Isidro pierde una parte de su profesorado que se incorpora como catedráticos de la Universidad, mientras que para el Instituto del Cardenal Cisneros se buscan profesores con experiencia y reconocido prestigio como Alberto Lista, A. A. Camús y Juan Chavarri.

4. El Instituto de San Isidro pierde material científico pues ha de compartir con la Facultad de Ciencias y el Instituto del Cardenal Cisneros los instrumentos de física. En este sentido recordamos que en los Reales Estudios de San Isidro se impartían estudios de Física Experimental desde el reinado de Carlos III bajo el lema "Omnia docere», enseñar todas las cosas.

El plan de estudios de 1845 supone para los profesores de los institutos madrileños ciertos privilegios pues convierte sus cátedras en objeto de deseo para los profesores de otros institutos: mayores sueldos, mayor posibilidad para la publicación de manuales escolares y de promoción personal, en efecto, estos institutos se convierten en el puente de acceso a la Universidad Central y en centros de tránsito del saber pero también de gestión de poder, entre sus profesores encontramos políticos, académicos, ateneístas ${ }^{6} \ldots$

\section{ARQUITECTURA Y PEDAGOGIA}

Para el visitante, la primera diferencia que se establece entre los dos institutos es la arquitectónica. El edificio del Instituto San Isidro es una magnífica obra representativa del barroco herreriano. Fue construido por Francisco Bautista y Melchor de Bueras al mismo tiempo que la basílica de San Isidro, que originariamente fue iglesia del Colegio. El claustro es la parte más antigua que se conserva, se trata de un patio cuadrado enmarcado con veinte arcos en la parte inferior y veinte grandes balcones en la parte superior. Además se conservan la cripta, la biblioteca y la escalera imperial que en la actualidad, se ha destinado para un Museo de la Ciencia y de la Pedagogía, lugar privilegiado para convertirse en escaparate donde se expone parte de las ricas colecciones del centro.

La capilla del Instituto del San Isidro está presente en la memoria de todos por la descripción literaria que de ella realiza Pio Baroja en El árbol de la ciencia. La decoración de la bóveda es una gran puesta en escena, un auténtico decorado teatral. En su parte inferior, el artista creó una galería arquitectónica de formas rotundas, mientras que la superior asemejó un techo abierto hacia el cielo. Entre los

\footnotetext{
${ }^{6}$ RODRÍGUEZ GUERRERO, Carmen, «De la memoria y el olvido .La conservación del patrimonio educativo", en Revista Pátina, Escuela Superior de Conservación y Restauración de Bienes Culturales de Madrid -España, 2011, pp. 123-139.
} 
múltiples personajes que aparecen representados se encuentran diecisiete santos fundadores, de los cuales solo dos son mujeres, colocadas en la cabecera de la capilla ${ }^{7}$. Por su parte, el edificio del Instituto del Cardenal Cisneros comienza a ser construido por Jareño en 1877, situado entre la Plaza de España y San Bernardo resulta invisible al primer golpe de vista del paseante, quedando oculto como uno más entre otros edificios de la zona. Solo los curiosos conocen que hay muros que ocultan historias y una mirada a su interior nos ha de narrar una historia de la pedagogía para aquellos que la queremos leer. Su singularidad radica en que se ha conservado tal y como fue concebido, y, así, se presenta, en su exterior, en un austero color rojizo que contrasta con la luminosidad de su interior, espacio ennoblecido con suelos de mármol blanco y maderas nobles, en el la escalera es el gran recibidor, espacio magnificente que constituye la primera impresión que recibe el alumno. Consta de tres tramos con dos mesetas: el primer tramo esta adosado al muro y la primera meseta es la encargada de distribuir los alumnos por las aulas del primer piso. En la segunda meseta se desdobla, para encontramos al final un amplio espacio coronado por tres vidrieras de José Maumejean. Austera en la ornamentación, sobria, con solidas columnas de piedra, nos muestra una decoración sin concesiones a lo frívolo como la actividad que se desarrolla allí: la educación de las jóvenes generaciones ${ }^{8}$.

\section{LO BELLO Y LO ÚTIL EN EL INSTITUTO DE SAN ISIDRO}

En el siglo XIX el peso de los alumnos que cursan el bachillerato en Madrid no llega al $5 \%$ del total de la población en edad de estar escolarizada en ese nivel, por otra parte en Francia se ofrecen datos similares, son estudios cuyos costes económicos estaban al alcance de muy pocos. Conviene recordar que hablamos de la educación de élites masculinas, jóvenes patricios encargados de conservar las condiciones del país y de la clase social a la que pertenecen.

Desde 1845 hasta 1858 se define la adscripción de alumnos y colegios privados a los institutos madrileños, y se acuerda que si trazamos una línea imaginaria desde el paseo del Prado, la carrera de San Jerónimo, la Puerta del Sol y la calle Mayor hasta Palacio, la zona sur, tradicionalmente conocida por el nombre de sus habitantes, los manolos, estos serán el vivero que ha de nutrir el alumnado del Instituto de San Isidro. Los residentes del cuartel Norte, se les conocía por los chisperos, y les correspondía matricularse en el Instituto Cardenal Cisneros.

Nada de particular tiene que la oferta educativa de los institutos de Madrid se refiera al bachillerato clásico, humanístico aderezado con enseñanzas de adorno

\footnotetext{
${ }^{7}$ MARTIN VILLA, Rafael, op cit, p.63.

${ }^{8}$ RODRÍGUEZ GUERRERO, Carmen, «El Instituto del Cardenal Cisneros: la puesta en valor de un patrimonio singular», en LÓPEZ- OCÓN CABRERA, Leoncio, (ed) Aulas con memoria .Ciencia, educación y patrimonio en los institutos históricos de Madrid (1837-1936). CEIMES, CSIC, Comunidad de Madrid, 2012, pp 117-134.
} 
como la esgrima, lenguas vivas de inglés francés, italiano y alemán, asignaturas que perviven, si bien, en nuestros días cumplen con otra funciones a las asignadas originariamente. Esta oferta se mantiene en virtud del fin de la institución y del perfil del alumno matriculado: se trata de educar al gentleman, el caballero culto que va a ocupar los máximos puestos de responsabilidad en la sociedad, tanto en los foros políticos, eclesiásticos, militares, e intelectuales.

De esta forma las asignaturas que se ofrecen en los dos institutos, con variantes según el plan de estudios, serán: Gramática Castellana y rudimentos de Lengua Latina; Cálculo y nociones elementales de Geometría y Álgebra, Trigonometría rectilínea, Elementos de Geografía, Mitología y principios de Historia General, Principios de Psicología, Ideología y Lógica; Lengua Francesa, Nociones de Historia Natural, Elementos de Física con nociones de Química , Elementos de Retórica y Poética y Griego. Las doce cátedras de los estudios generales de los dos institutos madrileños coinciden y ambos expiden el título de bachiller, únicas instituciones que pueden otorgarlo en Madrid.

Ningún concepto de arte ni de cultura encontramos en los Programas para las asignaturas de segunda enseñanza, de hecho al profesor de Historia le corresponde «ejercitar la memoria de los alumnos para que procuren conservar en ella los datos más interesantes; pero sin detenerse en largos comentarios ni en teorías filosóficas»?.

Ahora bien, en el Instituto de San Isidro además de las asignaturas ya descritas, se ofrece Taquigrafía, Aritmética y teneduría de libros, Estadística comercial, Economía política y Legislación mercantil y Dibujo lineal y Delineación que conducen al título de perito. Y, desde 1857 que se promulga la ley Moyano, es precisamente en los trabajos escolares realizados por los alumnos en esta última asignatura donde encontramos que las primeras nociones de arte se asocian a la reproducción de elementos arquitectónicos y escultóricos, elementos artísticos y ornamentales.

El arte es útil en las aulas para aprender proporciones, técnicas y otros conocimientos necesarios para los futuros peritos y arquitectos. No se imparten conceptos teóricos, ni de estética, ni tampoco de historia del arte. Esos no son los objetivos que se marca el catedrático de la asignatura Mariano Borrell en su manual escolar «Tratado teórico-práctico de dibujo con aplicaciones a las artes y la industria»10.

\footnotetext{
${ }^{9}$ Nos referimos a los Programas de segunda enseñanza mandadas observar por su majestad en todos los institutos, seminarios y colegios por Real Orden del 20 septiembre de 1850. Madrid, Imprenta Nacional.

${ }^{10}$ BORRELL, Mariano. Tratado teórico y práctico de dibujo con aplicación á las artes y á la industria, Madrid, Imprenta y estereotipia de M. Rivadeneyra, 1866-1869. La profesora y jefa de estudios del Instituto de San Isidro, Ma José Gómez Redondo se encuentra realizando una investigación acerca de este profesor, sus trabajos escolares y libros de texto que verá la luz en los próximos meses. Una selección de las láminas de Dibujo del siglo XIX del IES. San Isidro de Madrid https://picasaweb.google.com/109200301032655860788/LaminasDeDibujoDelXIXInstitutoSanIsidro.
} 


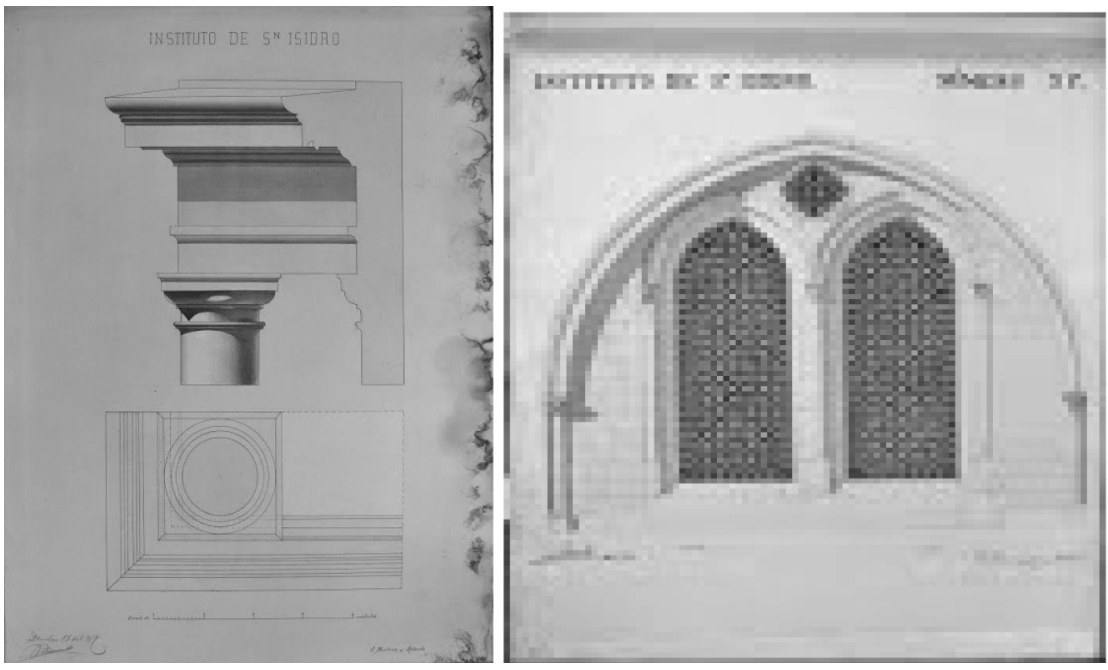

Trabajos escolares IES San Isidro 1859-1860

Fotos: Ma José Gómez Redondo

Por otra parte, nada referente a términos artísticos, estéticos o culturales encontramos en los libros de texto de los catedráticos de Madrid en esos años: Verdejo Páez en el Instituto del Cardenal Cisneros y Fernando de Castro ${ }^{11}$, Mariano Huerta Soriano, Remigio Ramírez González y Bautista Guardiola en el Instituto de San Isidro. Estos libros se nutren principalmente de la tradición y la leyenda, son manuales con cantidad de detalles, de guerras y héroes, santos y reyes ordenados de forma cronológica para su mejor memorización.

\section{EL SEXENIO DEMOCRATICO Y LA ASIGNATURA DE PRINCIPIOS DE ARTE}

Antes de nada, debemos anotar que los años de convulsiones políticas del Sexenio Democrático traerán a las instituciones educativas madrileñas grandes cambios, principalmente al Instituto del Cardenal Cisneros. Los profesores demócratas y krausistas convierten esta institución educativa en un laboratorio de experimentación de sus idearios y, de punto de partida, nombran para el cargo de director a Moya de la Torre, catedrático de matemáticas, progresista afín a las tesis de Cris-

${ }^{11}$ CASTRO Y PAJARES, Fernando de. Historia profana general y particular de España. 5a ed. Madrid: Imprenta de Manuel Galiano, 1858, XXIV 630 p. Declarada de texto para uso de los institutos y colegios de segunda enseñanza. En la 6ª edición, si encontramos conocimientos de la civilización y en las ediciones de finales de siglo, pues tras el fallecimiento del autor le dan continuidad a este libro Manuel Sales Ferré y Suárez de Toledo. 
tino Martos y firme seguidor de las propuestas de renovación pedagógica del rector krausista, Fernando de Castro.

Encontramos varias publicaciones ${ }^{12}$ sobre los estudios de historia del arte durante el Sexenio, de ellos daremos cuenta, pero nuestra mirada va a tratar de contextualizar las razones para la aparición de estos estudios que vienen determinados desde las innovaciones que se producen en la concepción de la propia etapa educativa. En la reforma progresista, el ministro Ruiz Zorrilla firma dos sistemas de Bachillerato ${ }^{13}$ :

1. El Bachillerato clásico, que supone la continuidad del que se está impartiendo, con la salvedad de la asignatura de Religión, que desaparece, y la incorporación de la de Fisiología e Higiene, cumpliendo aquella máxima de «más agua y jabón y menos religión».

2. El Segundo Sistema de Bachillerato, o Bachillerato Moderno, sin las disciplinas de religión ni latín.

El citado decreto permite la libertad de elegir uno u otro sistema a los institutos del país, a excepción de Madrid, de cuyos dos únicos institutos existentes, el de San Isidro o el de Noviciado, uno ha de experimentar el bachillerato moderno. En los Archivos del Instituto del Cardenal Cisneros comprobamos que el director Moya de la Torre ofrece esta institución a la Diputación Provincial para ensayar el Segundo Sistema de Bachillerato. Y, el 28 de octubre se acuerda «designar al Instituto del Noviciado para que en él se imparta el nuevo Sistema de Bachillerato, y que en San Isidro se dé lo marcado en la ley del 9 de septiembre de 1857, sin la asignatura de religión ${ }^{14}$.

Este director entiende que el bachillerato moderno forma parte de una estrategia global de transformación de los hombres que, educados, serían los núcleos iniciales en los que cristalizarían la renovación española y que, esparcidos por todo el país, se irían poco a poco ganando a la juventud española por la superioridad de sus propuestas intelectuales y morales ${ }^{15}$. Creemos ver que en el Instituto del No-

12 CABALLERO CARRILLO, María Rosario. «La Historia del Arte en la enseñanza secundaria: perspectiva histórica y posibilidades de futuro", Imafronte. (1992), no 8 y 9, pp. 51-60 CABALLERO CARRILLO, María Rosario, «El primer manual de Historia del Arte con destino a Bachillerato. Su autor: Hermenegildo Giner de los Ríos», Imafronte, 2000, nำ15 pp. 17-27, SÁNCHEZ DE ANDRÉS, Leticia, «Manuales de origen Krausista para la enseñanza de la Estética, historia del Arte y de la Música en Bachillerato", en Arbor-CSIC, Ciencia, pensamiento y Cultura, 2011, vol. 187, pp. 535-545, y SÁNCHEZ DE ANDRÉS, Leticia, «La educación estética y musical en los institutos madrileños de la órbita krausista o institucionalista» en LÓPEZ-OCÓN CABRERA, Leoncio et allí, Aulas con memoria. Ciencia, educación y patrimonio en los institutos históricos de Madrid (1837-1936), Madrid, CEIMES, CSIC, Comunidad de Madrid, 2012, pp. 337-347.

13 «Decreto, de 25 de octubre de 1868, reorganizando los estudios de segunda enseñanza», en Colección Legislativa de España, Madrid, Imp. de Gracia y Justicia, t. C, p. 416-424.

${ }^{14}$ MOYA DE LA TORRE, Ambrosio. Archivo del Instituto del Cardenal Cisneros. Legajo s/c .Carpeta de Directores.

${ }^{15}$ MOYA DE LA TORRE, Ambrosio. Discurso Inaugural incluido en la Memoria Anual del Instituto de $1^{a}$ clase del Noviciado, curso1868-1869, Madrid, Imprenta de Segundo Martínez, 1869, p. 9. 
viciado es el lugar donde se enlaza el movimiento krausista con su plasmación práctica hasta el punto de pretender convertir el Instituto en un templo dedicado a la ciencia, la moralidad y al trabajo ${ }^{16}$.

Y para ello las innovaciones que el sistema de bachillerato moderno introduce respecto al bachillerato clásico son:

1. Supresión de las asignaturas de Latín, y Religión y Moral católica.

2. Transformar la asignatura de Retórica y Poética en Literatura que incluye Estética, Crítica y Historia de la Literatura, según el Programa diseñado por Giner de los Ríos y Manuel de la Revilla ${ }^{17}$ en el Colegio Internacional en el curso $1866 / 67$.

3. Diseñar las asignaturas del bachillerato moderno:

Antropología y Cosmología surgen por la fe profunda en el progreso moral del hombre y la suposición de la bondad antropológica en este nuevo hombre, bondad que mediante la educación se traduciría en una revolución en la escala de valores y, por tanto, en una modificación de sus costumbres atávicas, La Biología se liga estrechamente a la Política y, por lo tanto, a la Ética. La filosofía que inspira este plan de estudios otorga a la Ciencia un alto valor. Sanz del Río considera a la Ciencia, junto con el Arte, como los dos cuerpos centrales de la Historia Universal. Coherentemente, pues, con este presupuesto la asignatura de Biología y Ética ha de estar presente en la segunda enseñanza, esta asignatura la impartía en el Instituto del Noviciado Nicolás Salmerón con el fin de «preparar suavemente una más sabia organización de la sociedad por la regeneración de la conciencia privada y pública» ${ }^{18}$.

\footnotetext{
${ }^{16}$ Las ideas krausistas acerca del fin y de los destinatarios de la segunda enseñanza son desarrolladas en forma de normativa legal por Manuel Merelo Calvo, catedrático de Historia del Instituto del Cardenal Cisneros, en las circulares que firma el 1, 2 y 3 de septiembre de 1869 como Director de Instrucción Pública. Entre ellas, el catedrático de Historia del Instituto del Noviciado apuesta claramente por universalizar la segunda enseñanza para:

1. Mermar el carácter exclusivo y aristocrático que diferencia la educación secundaria, es decir, habilitarla como instrumento para redistribuir el saber y, en consecuencia como factor de igualdad social.

2. Extender los valores democráticos que plantea la revolución de 1868.

${ }_{17}$ Acerca de las modificaciones curriculares en los estudios literarios en secundaria puede consultarse REVILLA, Manuel de la, y ALCÁNTARA GARCíA, Pedro de, Principios de literatura general e Historia de la literatura española, Madrid, Tipografía del Colegio Nacional de Sordomudos y de Ciegos, 1872. Segunda edición, aumentada y completamente refundida. Madrid, 1877, 2 vols. 4ำ Madrid: (Imprenta de Pascual Conesa, editado expresamente para esta asignatura, asimismo en la Biblioteca Histórica del Instituto del Cardenal Cisneros se conserva un manuscrito de los Apuntes de la clase de Literatura del curso $1868-1869$ y GINER DE LOS RÍOS, Francisco, «Plan para estudio de un curso de principios elementales de Literatura de 1867», en GINER DE LOS RIOS, Francisco, Obras Completas, Madrid: Espasa-Calpe. 1936, tomo III, pp. 141-158.

${ }^{18}$ SALMERÓN ALONSO, Nicolás. La Universidad en el Estado, en La Enseñanza, año I, 25 de octubre de 1868, p. 21.
} 
A la vez, incorporar las asignaturas de Nociones de Derecho que se impartirá en dos cursos con el objetivo de contribuir a hacer ciudadanos aptos para ejercer los derechos y deberes políticos, Agricultura, Industria y Comercio y Principios del Arte y su Historia, para desarrollar la sensibilidad artística del alumno.

Todas estas asignaturas se pueden agrupar en torno a tres grandes principios: el hombre, la sociedad y la naturaleza. Del conocimiento del hombre surge el campo de las humanidades, en cuyo estudio se adquiere instrucción, seguridad en el pensar, delicadeza en sentir lo bello y gusto por expresarlo en la literatura y en el arte. Son asignaturas de este campo: Principios de Arte y Literatura, incorporando la educación estética, la filosofía y la historia en las dos disciplinas.

El eje de la sociedad organizaría las asignaturas económico-jurídicas, poniendo en relación lo individual con lo social, mostrando el lado práctico de los negocios a la vez que iniciando al alumno en su formación como ciudadano. Son asignaturas de este campo: Derecho, Agricultura, Industria y Comercio. Del principio de la Naturaleza, en cuya atmósfera vive el hombre y los seres que le rodean, surgen las ciencias físico-matemáticas y naturales: Biología y Ética, Matemáticas, Física y Química, Fisiología e Higiene.

La rápida multiplicación de asignaturas y la necesidad de profesores formados para impartirlas se suple gracias a los esfuerzos de algunos catedráticos que voluntariamente doblaron su horario -Merelo Calvo, Galdo López de Neira, Fernández-Vallín y el mismo Moya de la Torre- o bien «al crecido número de profesores auxiliares aptos, idóneos, adornados de ventajosas dotes, catedráticos de la Universidad Central, que aceptaron gustosos sus cargos desempeñándolos gratuitamente en beneficio de la instrucción general» ${ }^{19}$. Los profesores auxiliares para estas materias son: Francisco Giner de los Ríos para la asignatura de «Principios del Arte y su historia con especial mención a España», Manuel de la Revilla ${ }^{20}$ para «Literatura General y de España», Nicolás Salmerón Alonso para «Biología y Ética», Eusebio Ruiz Chamorro ${ }^{21}$ para «Antropología», Urbano González Serrano ${ }^{22}$ para Lógica, Miguel Carmona ${ }^{23}$ para de Derecho I y II y Eulogio Jiménez Sánchez ${ }^{24}$ para Aritmética y Trigonometría.

${ }^{19}$ MOYA DE LA TORRE, Ambrosio, Discurso inaugural incluido en la Memoria acerca del estado... curso 1869-1870, op. cit., p. 7.

${ }^{20}$ Manuel de la Revilla, hijo del profesor krausista José de la Revilla, alumno y profesor auxiliar del Instituto del Noviciado y catedrático de la Universidad Central,

${ }^{21}$ Eusebio Ruiz Chamorro, discípulo de Sanz del Río que se sitúa a la izquierda más radical del krausismo. Fue catedrático de Filosofía del Instituto del Noviciado a partir de 1873, firme defensor de las libertad en educación, fue amonestado en distintas ocasiones por negarse a utilizar libro de texto, por no usar traje académico y por negar la infalibilidad del Papa. Estuvo implicado en la Segunda Cuestión Universitaria.

${ }^{22}$ Urbano González Serrano, situado también a la izquierda del krausismo, colaborador de Francisco Giner, reconocido ateneísta y catedrático de Filosofía del Instituto de San Isidro a partir de 1873, estuvo implicado en la Segunda Cuestión Universitaria.

${ }^{23}$ Miguel Carmona discípulo muy allegado de Sanz del Río, del que fue albacea testamentario. 
Fijémonos ahora en los Libros de matriculas de los alumnos y en las Actas de los exámenes de los tribunales del Instituto del Cardenal Cisneros, comprobaremos que los alumnos que se examinan en el bachillerato moderno proceden principalmente del Colegio Internacional y algunos de enseñanza oficial. Los apellidos de estos alumnos corresponden a Jiménez de Vargas, Ruiz Chamorro, Martín Romero, Merelo Talavera..., hijos de profesores o intelectuales krausistas destacados. Sólo 15 alumnos de la enseñanza oficial y 7 de la privada cursaron la asignatura de Principios de Arte.

En 1877, la nueva política de la Restauración pone fin a una experiencia educativa y también a todo un proyecto de reforma de la segunda enseñanza oficial. Y efectivamente, el experimento no dio los frutos esperados por falta de alumnos matriculados. Nosotros entendemos que varios son los factores que limitan el éxito de este ensayo pedagógico.

- En primer lugar, cualquier intento de modernizar la enseñanza oficial no parte de cero, muy al contrario, debe contar con las inercias, costumbres y derechos adquiridos por el profesorado que se repiten por tradición en los centros y que son determinantes a la hora de incorporar cualquier reforma.

- En segundo lugar, la falta de formación específica del profesorado para el ejercicio de la docencia en la enseñanza secundaria.

- Finalmente las limitaciones económicas determinaron que con presupuestos muy escasos se deban impartir más asignaturas, y esto exige más profesores y más recursos materiales. El Tesoro Público y las Diputaciones Provinciales no pueden asumir los gastos de los institutos ${ }^{25}$. Ahora bien, la influencia y la presencia de Francisco Giner de los Ríos es directa y años después valorará las aportaciones del plan de estudios que aporta «tal vez antes de que en ningún otro pueblo, la enseñanza del Derecho y del Arte» ${ }^{26}$.

Uno de las innovaciones que se producen durante este periodo y que va a perdurar fue el introducir el concepto de civilización, y ello viene de la mano del libro de texto de Merelo Calvo ${ }^{27}$, catedrático de Historia y progresista, que pretende enseñar a sus alumnos más de los pueblos que de los personajes, que escribe en su manual que el verdadero sujeto de la historia no es el héroe sino el pueblo entero,

\footnotetext{
${ }^{24}$ Eulogio Jiménez Sánchez, krausista, matemático en el Observatorio de Madrid, traduce del alemán con el catedrático Manuel Merelo Calvo algunas obras de Matemáticas. Alumno del catedrático Ambrosio Moya de la Torre, escribe un libro de Matemáticas como ofrenda de gratitud a su profesor.

${ }^{25}$ RODRÍGUEZ GUERRERO, Carmen, El Instituto del Cardenal Cisneros de Madrid (1845-1877),. Madrid, Consejo Superior de Investigaciones Científicas, 2009.

${ }^{26}$ GINER DE LOS RÍOS, Francisco, «La Universidad Española» en GINER DE LOS RÍOS, Francisco, Obras completas, Madrid, Espasa Calpe, 1929, t. II, p. 26.

${ }^{27}$ MERELO CALVO, Manuel, Lecciones elementales de Historia Universal, Madrid, Agustín Jubera, 1872. Catedrático del Instituto Cardenal Cisneros entre los años 1857 y 1902, diputado, senador vitalicio , ministro de Estado durante la I Republica fue separado en 1876 por haber publicado un libro de texto de Historia de España que en su edición de 1873 «atenta contra la más alta institución del país».
} 
cuyo trabajo de conjunto produce la civilización. Para este catedrático civilizar es «transformar al hombre en ciudadano haciéndole conocer sus derechos y sus deberes». Introduce al final de cada edad un apéndice con el estado del progreso de las letras, las ciencias y las artes y presenta el proceso evolutivo de la cultura, entendiendo que la civilización, el progreso, no se realiza en línea recta ${ }^{28}$.

Por otra parte, ya es conocido que Francisco Giner de los Ríos va a sufrir una enfermedad mientras impartía las clases de Principios de Arte en el Instituto del Cardenal Cisneros por lo que va a ser sustituido por su hermano Hermenegildo. Fruto de esta experiencia didáctica y de su trabajo en la Institución Libre de Enseñanza va a ser el primer libro de texto publicado con destino al bachillerato ${ }^{29}$. Este manual escolar va a dividir los conceptos en dos partes una de Estética y Teoría, que se centra en los conceptos de filosofía del arte y que ya están recogidos por Manuel de la Revilla en el libro de Principios de Literatura ya citado, y una segunda parte, de Historia del Arte que comienza en el Orientalismo y el paganismo y concluye en Roma y la Historia de la música antigua ${ }^{30}$.

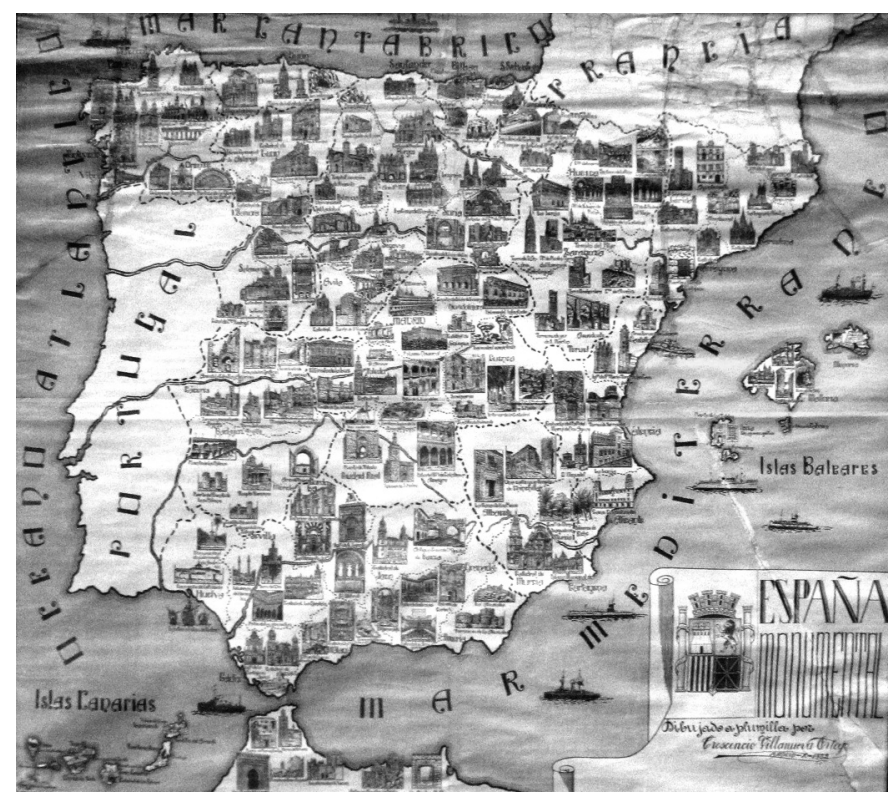

Mapa monumental de España

${ }^{28}$ RODRÍGUEZ GUERRERO, Carmen, El Instituto del Cardenal Cisneros de Madrid (1845-1877), Madrid, Consejo Superior de Investigaciones Científicas, 2009., pp.397-406

${ }^{29}$ CABALLERO CARRILLO, María Rosario, «El primer manual de Historia del Arte con destino a Bachillerato. Su autor: Hermenegildo Giner de los Ríos», Imafronte, 2000, n¹5 pp. 17-27.

30 SÁNCHEZ DE ANDRÉS, Leticia, «Manuales de origen Krausista para la enseñanza de la Estética, historia del Arte y de la Música en Bachillerato», Arbor-CSIC, Ciencia, pensamiento y Cultura, 2011, vol. 187, pp. 538-540. 


\section{EL RENACIMIENTO DEL INSTITUTO DEL CARDENAL CISNEROS Y LOS MATERIALES DE ARTE}

Tras el abrupto final del Sexenio, por el golpe de Estado del general Pavía, era necesario iniciar una nueva etapa en el Instituto del Cardenal Cisneros que tanto se había señalado en los años anteriores. Tres decisiones marcan el renacer de esta institución: el cambio de denominación, la construcción de un edificio propio y la participación en la Exposición Universal en Paris. Ciertamente que la asignatura de Historia del arte no se va a impartir en estos cursos pero va a estar presente por una parte, asociada a estos cambios y, por otra, a la redacción de algunos libros de texto.

Por lo que respecta al cambio de nombre, fue el ministro de Fomento y antiguo alumno, el conde de Toreno, quién decidió que en lo sucesivo el Instituto del Noviciado se denominara Instituto del Cardenal Cisneros y a este mismo ministro se debe la dotación para la construcción de un nuevo edificio siguiendo los planos del arquitecto Francisco Jareño, primero en escribir un tratado de arquitectura escolar en nuestro país. En estos actos se define la labor del Instituto del Cardenal Cisneros, "se trataba de formar hombres en los que se pudiera unir el amor a lo bueno, lo bello y lo verdadero y el inefable placer del estudio", educar al hombre ilustrado que Jovellanos hacia tan presente en su obra y que, enraíza con el humanismo de Cisneros, su labor de mecenazgo en las letras, en las ciencias y en el arte con la creación de la Universidad de Alcalá, hombre fuerte en la batalla y educado en la corte.

Fruto de este espíritu es el Álbum de recuerdos históricos elaborado por el catedrático de Geografía e Historia, Bernardo Monreal Ascaso. A modo de museo portátil podía presentar una colección iconográfica de láminas murales de los lugares por los que había dejado huella el cardenal Cisneros o escenas históricas en las que había intervenido: la universidad de Salamanca, San Juan de los Reyes y la Catedral de Toledo, la Capilla Real y la Alcazaba de Granada, el Palacio del Cardenal en Madrid, la Universidad y el Palacio arzobispal de Alcalá, y varios cuadros como La entrevista de Fernando el Católico con su hija, pintura de Vicente Palmaroli, o La conquista del Cardenal Cisneros de Francisco Jover, 2o premio en la exposición de 1871.

Todas estas láminas editadas en Francia por la casa Laurent, nos muestran una gran variedad de monumentos y, están especialmente diseñadas para España. Se pueden adquirir por épocas, por escuelas pictóricas o por grandes maestros, su precio es de cuatro pesetas.

Con este material el alumno puede formarse una idea aproximada de lo que fueron otros lugares y otros tiempos. Se trata de acercar el conocimiento histórico mediante las láminas, fotografías de sitios, monumentos y obras de arte que son una representación y vienen a suplir la realidad. En el caso de las láminas que formaban parte de este Álbum tienen el valor de la representación que se corresponde muy bien con el relato de los sucesos, y, por tanto, permite la concreción plástica de los hechos históricos. Presentarlas en un álbum viene a sustituir la di- 
ficultad del uso de las láminas murales , pues estas últimas para clases numerosas, como son las de los institutos madrileños que llegan a superar los 200 alumnos, cuando estos se encuentran alejados del lugar donde se cuelga la lámina, no pueden ver con nitidez aquello que representa.

$\mathrm{Y}$, como ya hemos reseñado, la enseñanza del arte se encuentra supeditada a apoyar los conocimientos de la asignatura de Historia y de Dibujo Lineal y de Adorno con la adquisición de materiales en los dos institutos madrileños como la colecciones de láminas arquitectónicas de J. Delarne y de Carot y las cromolitografías del Museo español de Antigüedades. La Memorias de estos institutos dan cuenta detallada de los materiales adquiridos y el gasto realizado con periodicidad anual ${ }^{31}$.

\section{EL DESEO, LA REALIDAD Y ESPAÑA MONUMENTAL}

Ciertamente, la asignatura de Historia del Arte con carácter autónomo no encuentra un lugar estable en el sistema educativo. Tras la experiencia efímera del Sexenio habrá que esperar al plan de estudios de 1894 para que se incluya una asignatura con la denominación de Teoría e Historia del Arte pero apenas transcurridos unos meses otro plan de estudios suprime el anterior para volver a incorporarse nuevamente la materia con la misma denominación en sexto curso en 1898 para desaparecer hasta la reforma de $1926^{32}$. El estudio del impacto de este continuo tejer y destejer de los planes de estudio en los institutos de Madrid ya ha sido estudiado ${ }^{33}$ y la lectura de las Memorias y otros documentos de los institutos madrileños nos muestran una realidad frustrante, el espacio de tiempo entre un plan de estudios y el siguiente no permiten realizar cambios en los institutos, los profesores se quejan por sentirse que son tratados como "satélites de la política». En cualquier caso, no encontramos la asignatura de Historia del Arte con carácter autónomo en los horarios de los Institutos de San Isidro y Cardenal Cisneros de Madrid, pues estos se ajustan a la normativa legal, y en ellos concurren inercias, resistencias y hasta una cierta estabilidad de los centros frente a los continuos cambios normativos.

Pero el citado plan de estudios de septiembre de 1894 tiene sus frutos, pues manda establecer un Museo de reproducciones en cada instituto y, la real orden de 28 de octubre del mismo año aclara el concepto de Museo escolar y propone que, además de las reproducciones de las principales pinturas y las láminas que hemos citado, se adquieran y expongan los materiales de la Calcografía Nacional. Hoy se conserva una colección de 29 grabados en el Instituto del Cardenal Cisneros ad-

\footnotetext{
${ }^{31}$ Una copia facsimilar de estas Memorias pueden consultarse en www bvpb.es, micrositio bibliotecas escolares históricas.

${ }^{32}$ CABALLERO CARRILLO, María Rosario. «La Historia del Arte en la enseñanza secundaria: perspectiva histórica y posibilidades de futuro», Imafronte, 1992, no 8 y 9, pp. 51-60.

${ }^{3}$ MORENO CASTAÑNO, Begoña y NÚÑEZZ, Clara Eugenia, «Los planes de estudio en la aparición y consolidación de la Enseñanza Secundaria: el Instituto Cardenal Cisneros de Madrid 1885-1938» Arbor, Vol 187, N.o 749, 2011, pp. 99-111.
} 


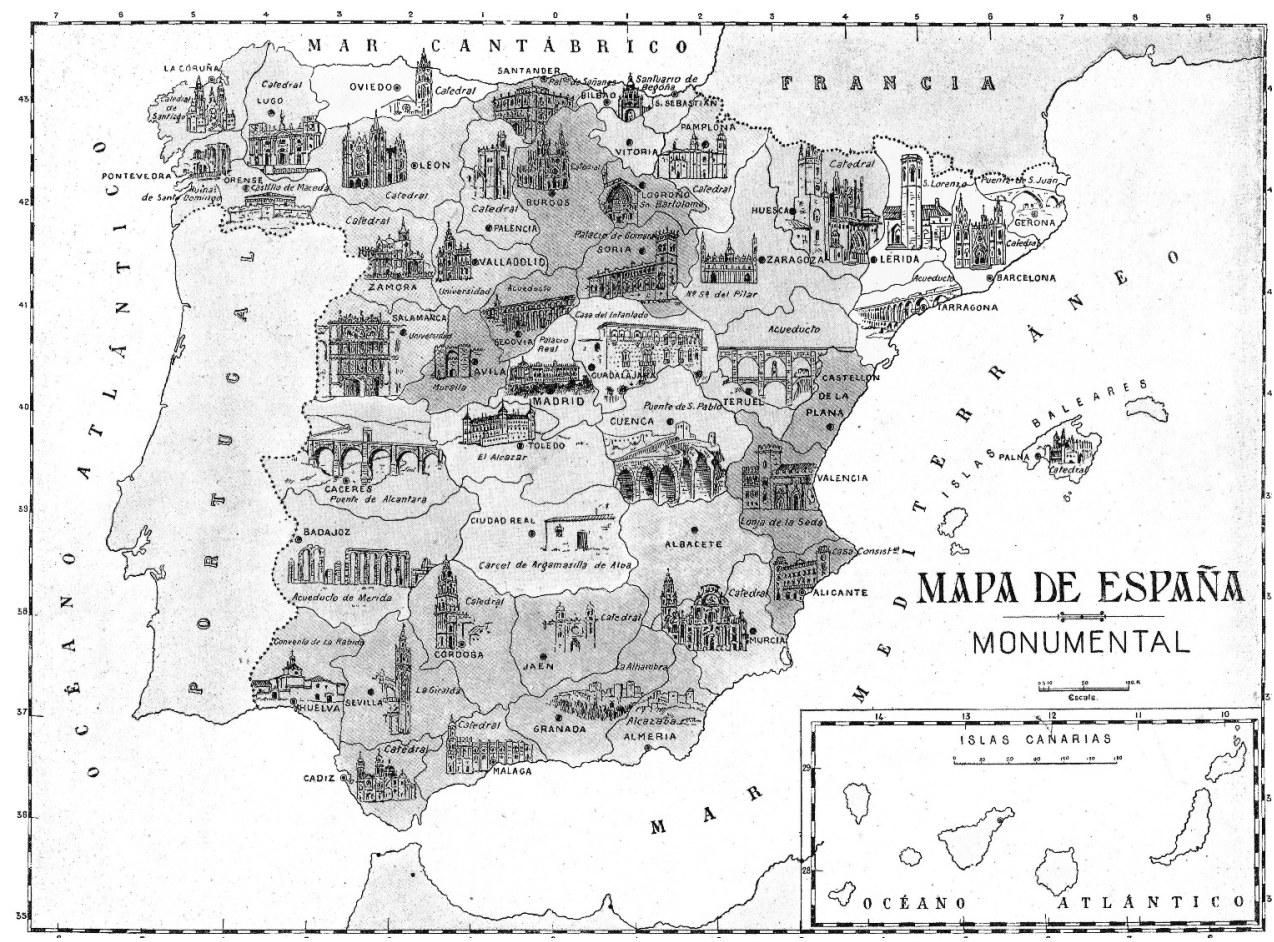

Foto : Atlas de geografía especial de España publicado en 1910 por el catedrático Esteban y Gómez

quiridos por mandato de esa real orden. También se adquieren una colección de vaciados y reproducciones en tamaño reducido de obra escultórica, arquitectónica y medallas, entre ellos Venus de Milo, el Discóbolo de Mirón, bustos de Apolo, Sófocles, Platón, Pensioroso de Miguel Ángel, capiteles y bajorrelieves del Partenón de Fidias, hasta el momento solamente conocemos los que se conservan en el Instituto Antonio Machado de Soria y fotografías de las galerías del Instituto Práxedes Mateo Sagasta de Logroño.

Los dos institutos de Madrid adquieren parte de estos materiales didácticos en la Escuela Central de Artes y Oficios y en el Museo de Reproducciones. Nuevamente el arte es útil, fija en la imaginación del alumno la sucesión de los hechos históricos, visualizar una imagen ayuda a memorizar y, así se recogen en los manuales escolares las primeras ilustraciones, y además, el objetivo didáctico de este Museo escolar es tratar de hacer vivir a los alumnos en un medio estético y, al igual que en Francia comienzan a decorarse las clases, los pasillos con las reproducciones de estas obras maestra. Decorar para educarse en un ambiente de belleza, para despertar el gusto por el arte desde la contemplación de esté. Algunos 
profesores reacios a esta forma de enseñar publican que a la curiosidad inicial de los alumnos pronto le siguió la indiferencia.

De los libros de texto publicados hemos de destacar el Atlas de geografía especial de España publicado en 1910 por el catedrático Esteban y Gómez ${ }^{34}$. Más de 30 mapas sobre diferentes aspectos geográficos de España y las colonias africanas nos permiten conocer a nuestro país desde distintos puntos de vista: físico (relieve, hidrografía, regiones climáticas, riquezas y aguas minerales, zonas de vegetación, regiones zoológicas); económico (agricultura, comercio, comunicaciones), político-administrativo (divisiones regional, marítima, eclesiástica, militar, judicial, docente), demográfico (densidad de población) y cultural (tasas de analfabetismo, monumentos, sitios pintorescos ${ }^{35}$ ).

Mapas que se repite en los libros de texto hasta bien entrado el siglo $X X^{36}$. Aquí presentamos un ejemplar dibujado a plumilla por Crescencio Villanueva Ortega publicado en 1932, ejemplar que se custodia en la mapoteca del Instituto del Cardenal Cisneros y una copia puede consultarse en www biblioteca virtual del patrimonio bibliográfico español, micrositio bibliotecas escolares históricas.

\section{EL EXCURSIONISMO ESCOLAR. LA PIEDRA QUE HABLA}

Desde fechas muy tempranas los Institutos de San Isidro y Cardenal Cisneros de Madrid participan del excursionismo escolar. En este sentido, una de las huellas que se conservan es la revista publicada por Manuel Zabala Urdániz, director y catedrático de Historia del Instituto de San Isidro publicada desde 1906. El excursionista escolar ${ }^{37}$ analiza el método de aprendizaje en el que se rompe el carácter enciclopédico y erudito de los estudios de enseñanzas medias y reconoce que la excursión tiene el valor de establecer la comunicación, valora la cercanía de los profesores y alumnos «ante la piedra que habla de los legendarios sucesos, y ante el monumento levantado para perpetuar un hecho histórico». Revista de escasa di-

${ }^{34}$ ESTEBAN Y GÓMEZ, José, Atlas de geografía especial de España para el estudio práctico de los alumnos de esta asignatura en los institutos, escuelas y demás centros de enseñanzas. Madrid, Imp. Eduardo Arias, 1910.

35 También se conserva un cuaderno, fechado en 1912, del alumno del Instituto Cardenal Cisneros, Juan Manuel de Villodas, contiene ejercicios prácticos de Geografía especial de España adaptados al plan del Atlas del catedrático de esa asignatura José Esteban y Gómez. Tomando como referencia ese Atlas el alumno ha llenado 30 mapas mudos, una copia digital de estos puede consultarse en www.ceimes.es.

${ }^{36}$ En nuestro país se elaboran pocos mapas, de ahí que gran parte de los que se conservan en los institutos madrileños comprobamos que España no es la protagonista, ni están detallados aspectos fundamentales de nuestra nación , excepción que realizamos con la colección de Torres Campos que comienzan a editarse desde 1889 y se adquieren y conservan en el Instituto del Cardenal Cisneros al precio de 38 pesetas la colección.

${ }^{37}$ El excursionista escolar. Revista decenal, el 1, 11 y 21 de cada mes Director Manuel Zabala Urdániz, Redacción y administración: Antonio Grillo, n.ㅇ 8, Madrid, 1906, Administrador Vicente Ballester de San Pantaleón. 
fusión que tiene como objetivo dar cuenta de las excursiones escolares que algunas instituciones educativas están realizando a Bilbao, Sagunto, Tarragona, El Escorial o Toledo. Sin duda, el nuevo método pedagógico trata de difundir los conocimientos mediante los sentidos y el sentimiento, la impresión, la emoción, el recuerdo de juventud y del centro docente donde se estudia.

Esta revista, sive para difundir noticias de las revistas europeas en torno al tema del excursionismo y apuesta por el intercambio de alumnos con carácter internacional para desarrollar relaciones de amistad personal que conducen a la amistad permanente entre naciones. Desde 1906, el Instituto de San Isidro solicita pensiones de estudio y cursos vacacionales para trasladar a sus alumnos a Francia e Inglaterra.

Otra revista profesional, que también se publica desde el Instituto del San Isidro es: La segunda enseñanza que se hace eco de las opiniones coincidentes de gran numero de de catedráticos de los institutos de España en 1922 y que redactan bajo el titulo de Bases para una reforma de la segunda enseñanza ${ }^{38}$. Entre las reivindicaciones se incorpora la necesidad de impartir una asignatura en $6^{\circ}$ y $7^{\circ}$ de bachillerato con la denominación de Historia del arte nacional. Los profesores, buscan en el alumno la admiración razonada de las grandes obras de artes plásticas como manifestaciones del espíritu humano, se trata de educar la sensibilidad.

Es probable que el legislador tuviera en cuenta parte de esta demanda en la reforma educativa de 1926 al establecer un sistema de bachillerato de seis cursos, dividido en dos niveles: elemental y superior y , será en $1^{\circ}$ de bachillerato superior donde se establezca la disciplina de Historia de la civilización española en sus relaciones con la universal.

Por otra parte, la revista de La segunda enseñanza informa de la situación de la educación en Europa y EEUU, a la vez que es un instrumento de formación del profesorado al incorporar experiencias didácticas realizadas por los profesores de los distintos institutos de España. Entre ellas, destacamos la que firma José Rogerio Sánchez, catedrático de Literatura y director de la revista, este propone para la lectura del Quijote ilustrar los viajes del Ingenioso Hidalgo con los principales monumentos de las provincias que recorre, situándolos en un mapa de España.

\section{LA MODERNIZACIÓN METODOLÓGICA EN LA HISTORIA DEL ARTE: LA IMAGEN AL SERVICIO DE LA NUEVA DISCIPLINA}

Como hemos visto hasta ahora en el Instituto del Cardenal Cisneros fundamentalmente, pero también el Instituto de San Isidro iniciaron una labor de in-

\footnotetext{
${ }^{38}$ La Segunda Enseñanza, Año I, n. 1, pp. 32-34.El consejo de redacción: Miguel Aguayo, Francisco Barnés. José Estalella, Vicente García de Diego, Manuel Manzanares, Manuel Sandoval y Luis Olles, el director: J. Rogerio Sánchez. Suscripciones en la Administración y en las librerías de Perlado y Páez y Victoriano Suárez, Madrid, 1922.
} 
novación pedagógica, el primero fruto de su estrecha vinculación con la Universidad Central y el segundo como centro más vinculado a las ciencias experimentales. Es ahí donde podemos situar el siguiente apartado sobre los aspectos más puramente metodológicos de la nueva asignatura de Historia del Arte. Nuevas materias, nuevos métodos. Si a esto añadimos la impronta de los nuevos momentos históricos que se estaban viviendo en la España de 1898, entendemos como la mayoría de estos cambios metodológicos se comprometían la renovación de la enseñanza.

De este modo el Instituto del Cardenal Cisneros y el de San Isidro pasan a convertirse en laboratorios de intensos ensayos pedagógicos, pasando hoy a salvaguardar el poso de la historia de la enseñanza media española, fruto de ese paso de figuras claves de la vida cultural y educativa de nuestro país que construyeron la nueva enseñanza en los nuevos institutos. En este camino de la historia educativa española, y madrileña en particular, ambos institutos atesoran hoy un valiosísimo patrimonio material, que desde libros a instrumentos científicos, pasando por objetos de la naturaleza más diversa han permanecido como muestra de ese deseo del fomento y transmisión del conocimiento en estos nuevos templos del saber en qué se convirtieron los institutos decimonónicos.

Es entre estos nuevos materiales se encuentran las protagonistas de una nueva metodología en la enseñanza de las ciencias naturales y de las ciencias sociales: las placas epidoscópicas o placas de linterna ${ }^{39}$. Estas placas de vidrio van a ser adquiridas desde 1880 por los profesores de diversos seminarios para servirse, igual que hoy, de la imagen al servicio del aprendizaje. Placas cuyo contenido oscila desde la biología a la historia, pasando por la historia del arte.

En las placas que conservan el Instituto Cardenal Cisneros y San Isidro se muestran todo un repertorio del patrimonio monumental español a través de las diversas provincias, museos o temas particulares de la historia del arte. Los fines con los que se realizan estas placas son la transmisión de conocimiento artístico, aunque desde luego cabe pensar en otros fines menos claros: como adquirir el conocimiento artístico español para ponerlo al servicio del engrandecimiento patrio. Conocer para exaltar la hundida autoestima nacional a finales del siglo XIX, al mismo tiempo que se inicia la toma de conciencia sobre el mal estado y poca valorización de nuestro patrimonio artístico. Todo ello a alumnos de institutos para que la educación artística y su utilidad en este aspecto comenzase desde la más temprana edad.

\footnotetext{
${ }^{39}$ Sobre la catalogación de las placas epidoscópicas existe el trabajo no publicado de Francisco Ruiz Collantes, profesor del Instituto Cardenal Cisneros.

${ }^{40}$ BENITO GOERLICH, Daniel. Coord. Arena numerosa: Colección de fotografía histórica de la Universitat de València. Valencia, Universidad de Valencia, 2006. pág. 75.
} 


\section{EDUCACIÓN A TRAVÉS DE LA MIRADA: EL EPIDIASCOPIO Y LAS PLACAS DE LINTERNA}

La fotografía y la imagen proyectada se incorporan a la práctica docente a mediados del siglo XIX, sobre todo a partir de 1857 con la Ley Moyano, donde las distintas facultades incluirán en sus gabinetes y laboratorios estos tipos de instrumentos como herramientas de investigación y docencia, al mismo tiempo que con ciertos aspectos lúdicos propios de aparatos extravagantes, insólitos hasta entonces con matices casi mágicos ${ }^{40}$.

En los institutos de Madrid se adquieren un poco más tarde, tenemos constancia de su uso desde 1880.Su proyección en el aula es de gran utilidad pues permite ilustrar el discurso del profesor y, además de ser entretenidas para el alumno, se podía observar el detalle y permitía identificar los distintos monumentos y estilos artísticos . Los profesores de Geografía e Historia las considerarían el complemento ideal para una asignatura con un fuerte contenido teórico y memorístico.

La fotografía (negativos de vidrio al colodión y placas secas al gelatino-bromuro) fue desde su aparición una absoluta revolución, cuyas aplicaciones científicas no se dejaron esperar. Una incipiente comunidad científica vinculada a la universidad y ésta a los recién creados institutos, que como el Cardenal Cisneros y del San Isidro compartiendo espacios y catedráticos con la Universidad Central, no escapó a la renovación metodológica que en la enseñanza se estaba produciendo. En resumidas cuentas la imagen (fotográfica o proyectada) pasó a considerarse como el motor revolucionario que la nueva pedagogía requería, entendiendo entonces que facilitaría el estudio de materias tan dispares como la Química, la Arqueología, la Matemática o la Historia del Arte.

La fotografía y el arte pronto iniciaron un intenso maridaje. En 1851 el gobierno francés encargó una catalogación monumental de Francia a través de la Comisión de Monumentos Históricos. La reproducción fotográfica de monumentos en España fue emprendida por J. Laurent, Hauser y Menet entre otros. Fotografía al servicio del arte tanto para dejar constancia, a modo de inventario artístico, de cómo era el estado de conservación entonces del patrimonio artístico en un momento en que la ruina, el expolio o la piqueta estaban a la orden del día. Del mismo modo la fotografía serviría para proveer de recurso previo a la restauración monumental. La fotografía de monumentos arquitectónicos desde el último tercio del siglo XIX será utilizada por las academias de Bellas Artes e institutos como herramienta cada vez más eficaz para la docencia de la Historia.

Si hoy en día la proyección de imágenes es algo habitual y fácil gracias a proyectores, la informática y las ya casi en desuso diapositivas, a mediados del siglo XIX las cosas no eran así de sencillas. La realidad entonces a pesar de los avances científicos y técnicos era mucho más compleja. Las placas de linterna se pueden considerar las precursoras de las diapositivas y, en los institutos, se aplican a la proyección de imágenes con fines didácticos. 


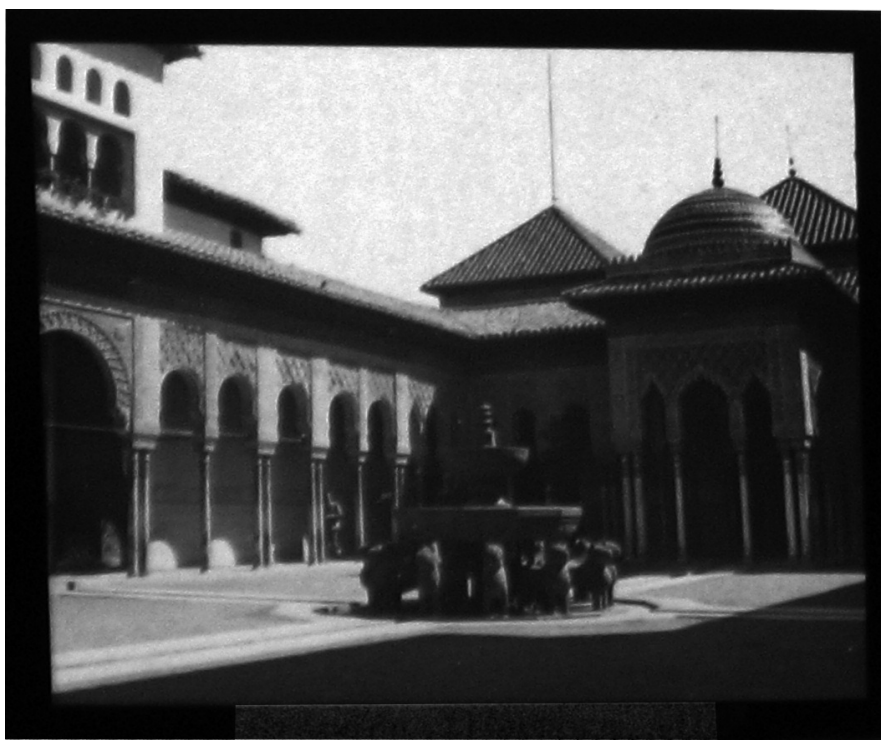

Patio de los leones. Placa epidioscópica. Colección AIDA

Este tipo de fotografías era una visión real y amplia, desconocida hasta entonces que permitía en el aula asomarse a culturas exóticas, ciudades lejanas, insectos minúsculos o escenas etnológicas que reflejaban el interés europeo por el conocimiento de esos territorios que estaba convirtiendo en colonias en pleno proceso imperialista. Sin embargo nuestro interés aquí radica en las placas de Historia del Arte español como material auxiliar que permitían conocer lugares fundamentales de nuestro patrimonio artístico sin salir de la clase en un momento donde los viajes a Segovia o Toledo, relativamente cerca, ya suponían un esfuerzo considerable tanto económico como de transporte y donde viajar a Galicia o aldeas vascas y no digamos al exterior, suponía toda una proeza característica del más intrépido viajero.

El numero de placas existente en el Instituto del Cardenal Cisneros supera los 2.000 ejemplares relativas a la historia e historia del arte, ordenadas por colecciones. Su proceso de recuperación, limpieza y catalogación fue arduo y costoso dado el mal estado en que se encontraban. Tras décadas de abandono, las placas estaban revueltas y dispersas por diversos cajones. La restauración se siguió teniendo en cuenta el orden de las colecciones según los catálogos comerciales de los fabricantes. Hoy se encuentran depositadas en un armario archivador de madera noble con tantos cajones como letras del abecedario y, están ordenadas por el título de sus colecciones. Las placas del las materias de Física y Química y de Ciencias Naturales se encuentran catalogadas y son visibles sus copias digitales en las plataformas His- 


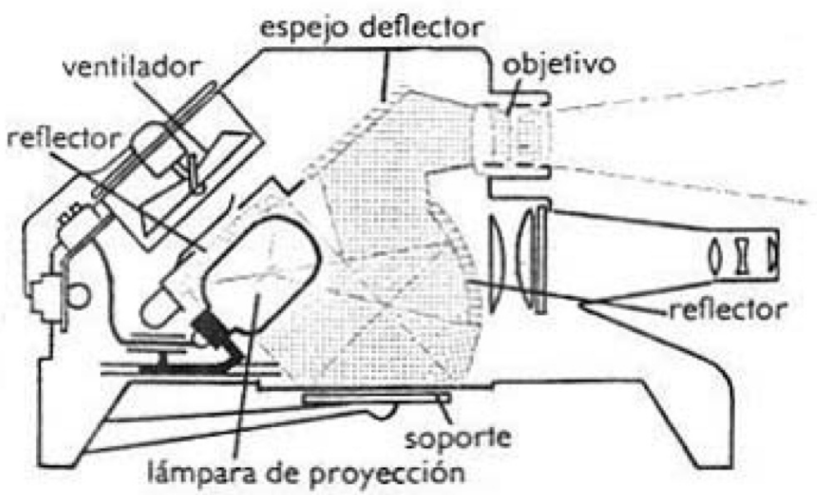

pana y Europeana, pero las que se refieren a la enseñanza de la Geografía e Historia se encuentran sin catalogar y por tanto sin digitalizar ${ }^{41}$.

Por otra parte, en el Instituto de San Isidro localizamos 104 colecciones de historia del arte, cada colección está compuesta por 12 ó 36 placas , si bien alguna está incompleta. Se encuentran limpias, ordenadas en sus cajas de madera originales y se puede acceder a estas a través del Catalogo Colectivo del Patrimonio Bibliográfico Español (CCPB)

Para aquellos que no han conocido una placa de linterna podemos describirla como un grabado, ilustración o copia fotográfica que constituye el motivo central y que se encuentra enmarcada por dos cristales de vidrio soplado y unidos por una tira adhesiva negra. Sus medidas oscilan entre $8,2 \times 8,2 \mathrm{~cm}$ o bien $8,2 \times 10 \mathrm{~cm}$. En el reverso de la placa lleva adherido una pequeña cartela con el nombre de quienes fueron sus fabricantes y el nombre de la ciudad o el monumento al que se refiere lo que nos permite datarlas para su catalogación, ahora bien , algunas de ellas han perdido la cartela o bien han sido construidas por los propios profesores, de ahí su dificultad para identificarlas .

Para su proyección se utilizaba un voluminoso aparato llamado epidiascopio (epi-dia-skope, ver a través de), es decir un proyector de cuerpos opacos con una utilidad para la proyección de gráficos, cuadros, imágenes de cualquier tipo que supongan un apoyo visual a la explicación del profesor. Posee un gran rendimiento luminoso pues funciona con una potente lámpara que lleva en su interior y tres espejos contrapuestos que concentran la luz producida por la lámpara $^{42}$. Para evitar el sobrecalentamiento del aparato en su interior poseía un ventilador. En el Instituto Cardenal Cisneros se conservan 5 aparatos de distintas épocas , sin ninguna duda , el que presenta una historia propia es el epidiascopio Adept Zeiss-Ikon de 1935 para placas de 8.5 que lleva escrito a gran tamaño:

${ }_{42}^{41}$ www.ceimes.es y http://bvpb.mcu.es/es/catalogo imagenes/grupo.cmd? posicion=25\&path=6743 
F.U.E. Las Memorias nos hablan de la existencia de otro que pertenecía a las Juventudes Socialistas que tan fuerte arraigo tuvieron en este Instituto, este último hoy se encuentra desaparecido.

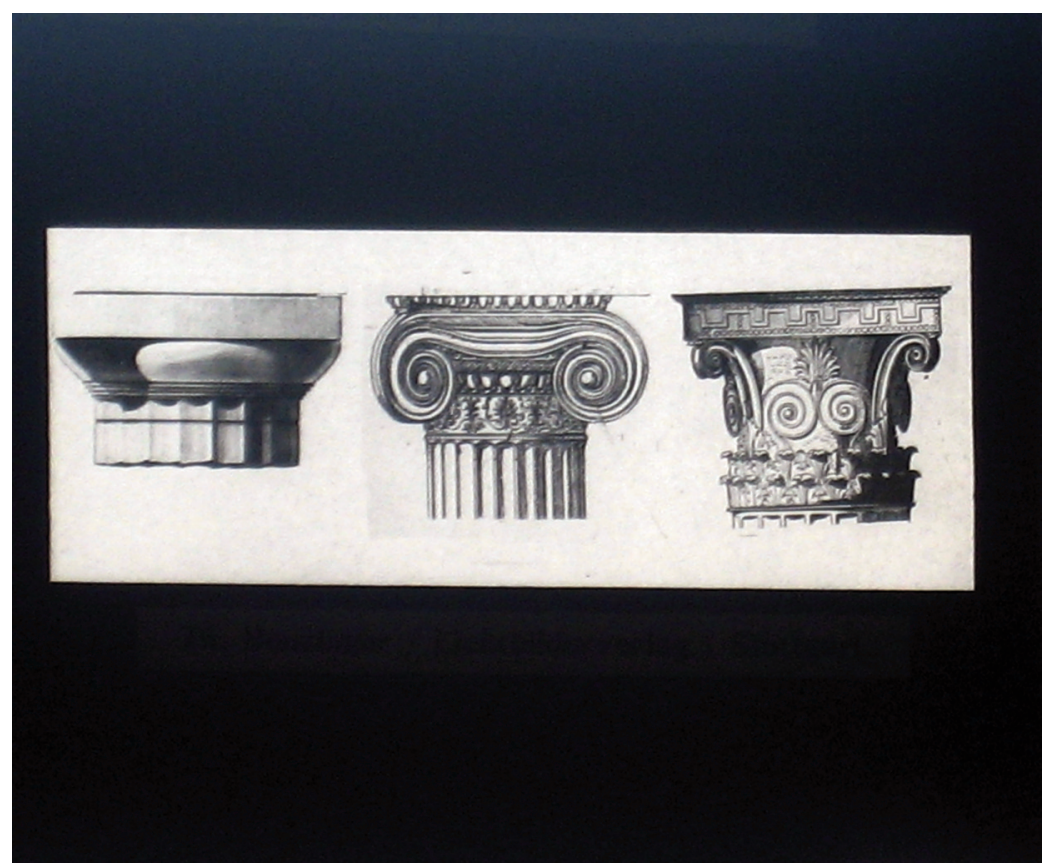

Placa epidioscópica de capitles clásicos. Colección BENZINGE

La placas de las que venimos hablando contienen imágenes con objetivos totalmente novedosos y útiles para la enseñanza: geografía, geología, química, física, botánica, biología, matemáticas, historiad de las civilizaciones e historia del arte. Placas de linterna utilizadas al servicio de la educación y provenientes de los principales distribuidores fotográficos del momento, que tanto en el caso de del Instituto Cardenal Cisneros como del San Isidro proceden de las siguientes casas: Aida; Benzinger; Bonne Presse; Dr. Neurirg; Lacoste Luiesegang; G.Massiot \&Cía; Projections Molteni; Mazo, y , las españolas, J. Esteva Marata; Sogeresa; Zubillaga; Espasa Calpe y Alfonso Vadillo43.

Las principales placas de linterna de Historia del Arte conservadas el Instituto Cardenal Cisneros pertenecen la distribuidora AIDA. Las placas se encuentras ca-

\footnotetext{
${ }^{43}$ RUIZ COLLANTES, F. Op. Cit. Pág. 9. Acerca de las casas de fabricantes puede consultarse el Informe de catalogación elaborado por SANTAMARIA ALMODA, R, El Archivo fotográfico del profesor Enrique Laguna Ferrari, curiosamente alumno de bachillerato del Instituto del Cardenal Cisneros.
} 
talogadas por provincias españolas desde Andalucía a Galicia pasando por todas y cada una de las regiones españolas. En ellas aparecen no solo las capitales de las provincias con sus monumentos más representativos, sino que aparecen pueblos y lugares que en muchos casos no han sido identificados al carecer del cartel que los identifique. Muchas de estas placas muestran edificios aún sin restaurar -la Alhambra de Granada o la catedral de León-, lo que aporta una importancia mayor a la colección. Pasemos a ver un ejemplo de lo que se ve de la provincia de Córdoba (observando aquí en qué se fijaban los profesores y qué querían mostrar a los alumnos). De esta provincia se conservan 18 placas: una de vista general, otra del arco de triunfo de la Puerta del Puente, tres del puente romano, otra del la Puerta de Sevilla, otra de la iglesia de San Nicolás, dos de la sinagoga, seis de la mezquita catedral (desde la torre, arcos y patio), otra de Medina Azahara, y dos del castillo de Montemayor. De Sevilla por ejemplo se conservan 29 placas: 16 de la catedral, 5 de los Reales Alcázares, 2 de Itálica y 6 de Carmona. En realidad la colección es muy completa y nos muestra una interesantísima metodología didáctica de la imagen de España utilizada como herramienta pedagógica de enorme valor.

Por otra parte, como ya hemos escrito el Instituto de San Isidro las colecciones de placas vinculadas a las materias de Historia, Geografía e Historia del Arte alcanzan la cifra de 104 colecciones de fabricantes muy variados . La mayoría de ellas pertenecen a la historia universal, que desde la Antigüedad a la Edad Contemporánea muestran historia política, eso sí, utilizando la historia del arte como soporte fundamental para demostrar la grandeza de esas civilizaciones. De la casa Mazo (primer cuarto del siglo XX) existen placas que tratan del Imperio Romano o Cartago mostrando edificios representativos tales como puentes, acueductos, calzadas, faros y puertos, arcos de triunfo, columnas, sepulcros, templos, teatros, circos, anfiteatros, termas, basílicas, murallas, foros y esculturas y mosaicos. De los medos y los persas, así como Babilonia aparecen en las placas destacándose tanto palacios in situ, como restos de estas culturas que se encuentran en el Museo del Louvre. También existen placas que retratan la Edad Media desde Avignon a las ciudades flamencas de Brujas o Ypres. De la casa Mazo existen una placa dedicada a España donde aparece Córdoba (mezquita y catedral); Sevilla (Giralda y Alcázares) y Granada (cinco placas sobre diversas salas de la Alhambra). Además las construidas por Mazo existen placas quizás más interesantes desde el punto de vista de la Historia del Arte que aquí nos interesa. Así, de Laurent nos encontramos como a finales del siglo XIX nos deja la huella de la pintura que en esos momentos se estaba realizando en España, como Sorolla o Agrasot; la Rendición de Bailén; o estampas de Madrid, principalmente del Palacio Real.

De finales del siglo XIX también existen en el Instituto San Isidro placas de la casa Massiot acerca de Goya como la Tirana o los grabados taurinos. Por último de la misma época también son las placas de la casa Molteni acerca de Florencia, Pisa, París y Córdoba. Sin embargo será Lacoste quien en 1910 deje el mayor testimonio en cuanto a placas de arte que posee este instituto con su serie sobre pintura del Museo del Prado centrado en dos áreas: Goya (Familia de Carlos IV, retratos reales, la 
pradera de San Isidro) y la pintura historicista del siglo XIX (Casado del Alisal, Moreno Carbonero, Álvarez Dumont). También aquí encontramos placas dedicadas a las regiones españolas aunque en muy menor cantidad, realizadas en la década de 1920 por Alfonso Vadillo sobre Salamanca, Burgos (ciudad, catedral y monasterio de las Huelgas) y Andalucía (como era habitual Córdoba, Sevilla y Granada únicamente).

Si bien es cierto que es difícil medir el impacto pedagógico de las placas de linterna cuando comienzan a utilizarse en las aulas, realmente debieron ser de una gran modernidad. Un soporte visual de gran ayuda para el profesor, pues facilita la trasmisión y comprensión de conceptos que eran difíciles de explicar sin poder ver los monumentos en la realidad, en un momento en que los viajes no eran algo común, las placas van a ser de gran utilidad en los institutos y las facultades hasta los años 1970. Con estas placas de linterna conservadas en los dos institutos madrileños protagonistas de nuestro artículo se educaron muchas generaciones de alumnos. Entre los que cabe destacar a Leopoldo Torres Balbás, los hermanos Fernández Balbuena y Félix Candela en el Instituto Cardenal Cisneros y Chueca Goitia en el San Isidro.

La educación artística se completa en el Instituto del Cardenal Cisneros desde 1932 con el cinematógrafo. Considerado un método pedagógico de gran valor para llegar a muchos alumnos en una sola proyección y en el que se aúnan enseñanza y recreo. Se programaban dos sesiones semanales en la tarde de los sábados para despertar la afición.

A propuesta del catedrático de Literatura, Mario Méndez Bejarano, se adquiere un aparato de proyección Mechau 4 ( A.E.G.), hoy en el Museo de la Ciencia y la Tecnología, y se proyectan documentales y películas instructivas suministradas por el Ministerio de Instrucción Pública o adquiridas por el propio Instituto. Títulos muy variados como "Grecia», "El emperador del mundo " 0 "La eucaristía y la Santa Misa».

También en el Instituto del Cardenal Cisneros se conservan películas con paisajes y temas de arte para ser proyectadas en la clase con el aparato Kodad hoy desaparecido. Las casa distribuidoras de estas películas son las francesas Editions de la Photoscopie y Filmette y las alemanas Stoedtener Film y Rothgiesser \& Schlossmann.

\section{CONCLUSIONES}

A lo largo de estas páginas se ha dejado constancia de las dificultades para introducir la disciplina de Historia del Arte con horario propio, currículo y profesores con formación específica en los institutos de bachillerato de Madrid. Aunque los profesores han entendido que la enseñanza del arte es útil y necesaria para el aprendizaje de otras asignaturas como el Dibujo y la Historia e incluso que com- 
parte lecciones del programa de Filosofía y Literatura, en los 33 planes de estudio que se promulgan en el periodo de cien años no encuentra un sitio con autonomía en los programas curriculares.

Y, además, pese a que en Madrid existían museos que permitían presentar lo fundamental de la materia con la emoción de la observación de las grandes obras de la historia de la pintura y de la escultura, a los profesores les era más fácil acudir con frecuencia a las representaciones como las fotografías, placas de linterna, mapas y las reproducciones de esculturas, es decir representaciones que sustituyen la realidad

Si a ello unimos el fuerte apego del profesorado a los libros de texto, creemos que introducir los conocimientos de Arte en las aulas fue posible al permutar las guerras por la cultura, cuando al catedrático publica manuales en los que se acentúa lo que hace o ha hecho cada nación por la civilización. En la medida que no se cuentan batallas y conquistadores, sino inventos y construcciones, es decir cuando dejan de ser libros de historia política es cuando los conocimientos de arte tienen mayor espacio en los manuales escolares.

$Y$, en este sentido se produce otro cambio, pues cuando los profesores de Historia comenzaron a creer que la memoria no era la única capacidad para el aprendizaje de su asignatura, cuando se comienza a visitar museos como centros de enseñanza viva, cuando se realizan excursiones es cuando surge el interés por la enseñanza artística.

De este modo se pretendía que poco a poco los ciudadanos que accedían a las enseñanzas medias fueran aprehendiendo conocimientos estéticos, asimilando ciertos valores artísticos y concienciándolos de la belleza e importancia de la patria, al mismo tiempo que se compara con la demás naciones, rescatando nuestro espléndido patrimonio artístico para ponerlo al servicio de la regeneración del país: recuperando el acervo colectivo al mismo tiempo que se produce una renovación en la mirada del mismo.

\section{BIBLIOGRAFÍA}

«Decreto, de 25 de octubre de 1868, reorganizando los estudios de segunda enseñanza», en Colección Legislativa de España, Madrid, Imp. de Gracia y Justicia, t. C, p. 416-424.

BENITO GOERLICH, Daniel. Coord. Arena numerosa: Colección de fotografía histórica de la Universitat de València. Valencia, Universidad de Valencia, 2006.

BORRELL, Mariano. Tratado teórico y práctico de dibujo con aplicación á las artes y á la industria, Madrid, Imprenta y estereotipia de M. Rivadeneyra, 1866-1869.

CABALLERO CARRILLO, María Rosario, «El primer manual de Historia del Arte con destino a BachiIlerato, Su autor: Hermenegildo Giner de los Ríos», Imafronte, 2000, nº15, pp. 17-27.

CABALLERO CARRILLO, María Rosario. «La Historia del Arte en la enseñanza secundaria: perspectiva histórica y posibilidades de futuro», Imafronte, 1992, no 8 y 9, pp. 51-60. 
CASTRO Y PAJARES, Fernando de, Historia profana general y particular de España. $5^{\text {a }}$ ed. Madrid: Imprenta de Manuel Galiano, 1858, XXIV $630 \mathrm{p}$.

El excursionista escolar. Revista decenal, el 1, 11 y 21 de cada mes Director Manuel Zabala Urdániz, Redacción y administración: Antonio Grillo, n. 8, Madrid, 1906, Administrador Vicente Ballester de San Pantaleón.

ESTEBAN Y GÓMEZ, José, Atlas de geografía especial de España para el estudio práctico de los alumnos de esta asignatura en los institutos, escuelas y demás centros de enseñanzas. Madrid, Imp. Eduardo Arias, 1910.

FADÓN GUERRA, Isidro, «El Instituto del Cardenal Cisneros de Madrid» en Revista Participación educativa oㅜ 7 del Consejo Escolar del Estado, Madrid 2007, pp. 55-59.

GINER DE LOS RÍOS, Francisco, «La Universidad Española» en GINER DE LOS RÍOS, Francisco, Obras completas, Madrid, Espasa Calpe, 1929, t. II, p.26.

GINER DE LOS RÍOS, Francisco, «Plan para estudio de un curso de principios elementales de Literatura de 1867», en GINER DE LOS RíOS, Francisco, Obras Completas, Madrid: Espasa-Calpe. 1936, tomo III, pp. 141-158.

La Segunda Enseñanza, Año I, n.ำ 1, pp. 32-34.El consejo de redacción: Miguel Aguayo, Francisco Barnés. José Estalella, Vicente García de Diego, Manuel Manzanares, Manuel Sandoval y Luis Olles, el director: J. Rogerio Sánchez. Suscripciones en la Administración y en las librerías de Perlado y Páez y Victoriano Suárez, Madrid, 1922.

MARTIN VILLA, Rafael, «El Instituto de San Isidro» en Revista Participación educativa, nº 7, Consejo Escolar del Estado y Ministerio de Educación, Madrid 2007, pp. 60-65,

MERELO CALVO, Manuel, Lecciones elementales de Historia Universal, Madrid, Agustín Jubera, 1872. MORENO CASTAÑO, Begoña y NÚÑEZ, Clara Eugenia, «Los planes de estudio en la aparición y consolidación de la Enseñanza Secundaria: el Instituto Cardenal Cisneros de Madrid 1885-1938» Arbor, Vol 187, N.․ 749, 2011.

MOYA DE LA TORRE, Ambrosio, Discurso inaugural incluido en la Memoria acerca del estado... curso 1869-1870, op. cit., p. 7.

MOYA DE LA TORRE, Ambrosio. Discurso Inaugural incluido en la Memoria Anual del Instituto de $1^{\underline{a}}$ clase del Noviciado, curso1868-1869, Madrid, Imprenta de Segundo Martínez, 1869.

RAMíREZ GONZÁLEZ, Remigio, Manual de Historia Universal, Madrid, Impr. de Hernando y Cía. 1897.

REVILLA, Manuel de la, y ALCÁNTARA GARCÍA, Pedro de, Principios de literatura general e Historia de la literatura española, Madrid, Tipografía del Colegio Nacional de Sordomudos y de Ciegos, 1872.

RODRÍGUEZ GUERRERO, Carmen, «De la memoria y el olvido. La conservación del patrimonio educativo», en Revista Pátina, Escuela Superior de Conservación y Restauración de Bienes Culturales de Madrid -España, 2011, pp. 123-139.

RODRÍGUEZ GUERRERO, Carmen, «El dos de mayo en las aulas de bachillerato de Madrid» en Madrid por la Libertad: Crónica Literaria: 1808-1814: Catálogo de Exposición. Madrid: Comunidad de. Madrid, 2008, pp. 152-183.

RODRÍGUEZ GUERRERO, Carmen, «El Instituto del Cardenal Cisneros: la puesta en valor de un patrimonio singular», en LÓPEZ- OCÓN CABRERA, Leoncio, (ed) Aulas con memoria .Ciencia, educación y patrimonio en los institutos históricos de Madrid (1837-1936). CEIMES, CSIC, Comunidad de Madrid, 2012, pp 117-134.

RODRÍGUEZ GUERRERO, Carmen, El Instituto del Cardenal Cisneros de Madrid (1845-1877),. Madrid, Consejo Superior de Investigaciones Científicas, 2009. 
RUIZ COLLANTES, Francisco, Las placas de linterna del IES Cardenal Cisneros. Trabajo inédito.

SALMERÓN ALONSO, Nicolás. La Universidad en el Estado, en La Enseñanza, año I, 25 de octubre de 1868, p. 21

SÁNCHEZ DE ANDRÉS, Leticia, "La educación estética y musical en los institutos madrileños de la órbita krausista o institucionalista» en LÓPEZ-OCÓN Leoncio et allí: Aulas con memoria. Ciencia, educación y patrimonio en los institutos históricos de Madrid (1837-1936). Madrid, CEIMES, CSIC, Comunidad de Madrid, 2012, pp. 337-347.

SÁNCHEZ DE ANDRÉS, Leticia, “Manuales de origen Krausista para la enseñanza de la Estética, Historia del Arte y de la Música en Bachillerato», Arbor-CSIC, Ciencia, pensamiento y Cultura, 2011, vol. 187, pp. 535-545.

SANTAMARIA ALMODA, Rosario, El Archivo fotográfico del profesor Enrique Laguna Ferrari, Trabajo inédito. Curiosamente Enrique Laguna Ferrari fue alumno de bachillerato del Instituto del Cardenal Cisneros.

UTANDE IGUALADA, Miguel, Planes de Estudio de enseñanza Media (1787-1963), Madrid, Ministerio de. Educación Nacional, Dirección General de Enseñanzas Medias, 1964.

www.ceimes.es

http://bvpb.mcu.es/es/catalogo_imagenes/grupo.cmd?posicion=25\&path=6743

https://picasaweb.google.com/109200301032655860788/LaminasDeDibujoDeIXIXInstitutoSanlsidro. 
